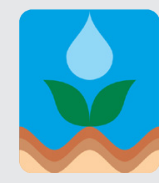

\author{
Revista Brasileira de Engenharia Agrícola e Ambiental \\ v.18, n.12, p.1274-1280, 2014 \\ Campina Grande, PB, UAEA/UFCG - http://www.agriambi.com.br \\ Protocolo 355.13 - 06/11/2013 • Aprovado em 04/07/2014
}

\title{
Inoculação de Pseudomonas fluorescens e adubação NPK na composição química e contaminação fungo-fumonisina de milho ${ }^{1}$
}

\author{
Luciana P. Bernd ${ }^{2}$, Thiago M. Souza ${ }^{3}$, Mariana A. de Oliveira', \\ Elisabete Y. S. Ono ${ }^{5}$, Claudemir Zucareli ${ }^{6}$ \& Elisa Y. Hirooka ${ }^{7}$ \\ ${ }^{1}$ Parte da Tese de Doutorado em Ciência de Alimentos do primeiro autor, apresentada à Universidade Estadual de Londrina, UEL, Londrina, PR \\ ${ }^{2}$ IFRS. Campus Bento Gonçalves, RS, BR. E-mail: luciana.bernd@bento.ifrs.edu.br (Autor correspondente) \\ ${ }^{3}$ FAPC/OSU. Stillwater, OK, USA. E-mail: thiagom@okstate.edu \\ ${ }^{4}$ CCA/UEL. Londrina, PR, BR. E-mail: agromariana.oliveira@hotmail.com \\ ${ }^{5}$ DBBTEC/CCE/UEL. Londrina, PR, BR. E-mail: eysono@uel.br \\ ${ }^{6}$ CCA/UEL. Londrina, PR, BR. E-mail: claudemircca@uel.br \\ ${ }^{7}$ DCTA/CCA/UEL. Londrina, PR, BR. E-mail: hiroooka@uel.br
}

Palavras-chave:

Zea mays L.

bactéria diazotrófica

adubação mineral

bromatologia, micotoxina

\begin{abstract}
R E S U M O
Propôs, neste trabalho, avaliar o efeito da inoculação de sementes com Pseudomonas fluorescens e adubação NPK (nitrogênio, fósforo e potássio) na composição química e contaminação por fungo-fumonisina de grãos de milho. O delineamento experimental foi bloco casualizado em fatorial 2 x 3, correspondente à inoculação com $P$. fluorecens (não inoculada ou inoculada) e níveis de adubação NPK (0, 125 e $250 \mathrm{~kg} \mathrm{ha}^{-1}$, formulados 08-28-16) com 4 repetições. Os parâmetros avaliados foram composição química (proteína e cinzas), contaminação fúngica (bolores e leveduras) e fumonisinas $\mathrm{B}_{1}\left(\mathrm{FB}_{1}\right)$ e $\mathrm{B}_{2}\left(\mathrm{FB}_{2}\right)$. Os dados foram submetidos à análise de variância, comparação de médias pelo teste de Tukey e correlação de Pearson, pelo teste- $\mathrm{t}(\mathrm{p}<0,05)$. Inoculação com $P$. fluorescens e adubação mineral não apresentaram efeito individual sobre os parâmetros avaliados $(\mathrm{p}>0,05)$. A interação entre fatores, com incremento no nível de adubação NPK e uso de P. Fluorescens, resultou em aumento no teor de cinzas e proteína $(\mathrm{p}<0,05)$ e reduziu a contaminação por leveduras no grão, favorecendo o crescimento de Fusarium spp. $(\mathrm{r}=-0,40$; $\mathrm{p}<0,05)$. Os níveis de fumonisinas totais $\left(\mathrm{FB}_{1}+\mathrm{FB}_{2}\right)$ observados estão enquadrados nos limites máximos tolerados, estabelecidos por órgãos de vigilância sanitária.
\end{abstract}

Key words:

Zea mays L. diazotrophic bacteria mineral fertilization bromatology mycotoxin

\section{Inoculation of Pseudomonas fluorescens and NPK fertilization on chemical composition and fungal-fumonisin contamination of maize}

\begin{abstract}
A B S T R A C T
The study aimed to evaluate the effect of inoculation of seeds with Pseudomonas fluorescens and NPK fertilization (nitrogen, phosphorus and potassium) on chemical composition and contamination by fungal-fumonisin of maize grains. The experiment was conducted in randomized block design in factorial $2 \times 3$, corresponding to inoculation with $P$. fluorescens (non-inoculated or inoculated) and levels of NPK fertilization $\left(0,125\right.$ and $250 \mathrm{~kg} \mathrm{ha}^{-1}$, formulation 8-28-16), with 4 replications. The parameters evaluated were chemical composition (protein and ash), contamination by fungal (mold and yeast) and fumonisins $\mathrm{B}_{1}\left(\mathrm{FB}_{1}\right)$ and $\mathrm{B}_{2}\left(\mathrm{FB}_{2}\right)$. The data were subjected to analysis of variance, comparisons of means by Tukey test and Pearson correlation by test- $\mathrm{t}(\mathrm{p}<0.05)$. Inoculation with $P$. fluorescens and mineral fertilizer as an isolated factor did not affect the parameters evaluated ( $p>0.05)$. The interaction between factors, increase in NPK level and use of $P$. fluorescens, resulted in increase in protein content and ash ( $\mathrm{p}<0.05)$, and reduction in contamination by yeast of the grain, favoring the growth of Fusarium sp. $(\mathrm{r}=-0.40, \mathrm{p}<0.05)$. The levels of total fumonisins $\left(\mathrm{FB}_{1}+\mathrm{FB}_{2}\right)$ observed are above the maximum tolerated limit established by health surveillance agencies.
\end{abstract}

\section{INTRODUÇÃO}

Qualidade nutricional, facilidade de adaptação e aplicabilidade fazem, do milho, cereal de importância mundial com destaque para os Estados Unidos, China e Brazil, entre os maiores produtores do cereal, com 313,9 (35,5\%), 192,8 $(21,8 \%)$ e $73,0(8,3 \%)$ milhões de toneladas na safra 2011/2012, respectivamente (USDA, 2013).
O milho, tal como outros cereais, é hospedeiro de espécies fúngicas produtoras de micotoxinas, como Fusarium verticillioides, principal contaminante do milho e produtor de fumonisinas, toxinas associadas aos feitos nocivos à saúde humana e animal (Norred, 1993). As fumonisinas, principalmente $\mathrm{FB}_{1}$, têm sido associadas às micotoxicoses em animais, como leucoencefalomalácia em equinos e síndrome de edema pulmonar em suínos. Em seres humanos têm sido 
relatados a ocorrência de câncer esofágico e defeitos do tubo neural de fetos (Waes et al., 2009). Em razão dos efeitos nocivos de Fusarium em culturas agrícolas, o controle de F. verticillioides e da produção de fumonisinas em milho tornou-se prioridade na investigação da segurança dos alimentos.

Objetivando redução da infecção por fitopatógenos em cereais, leguminosas e oleaginosas, as estratégias de controle são, em geral, baseadas no uso de pesticidas químicos (Kanampiu et al., 2002). Entretanto, o uso massivo desses produtos pode poluir as águas, degradar o solo e aumentar a resistência de insetos (Pereira et al., 2010).

As rizobactérias se apresentam com alternativa promissora de uso como agente de controle biológico, estando indiretamente relacionadas com a produção de metabólitos, como antibióticos, sideróforos e ácido hidrociânico, que diminuem o crescimento de fitopatógenos. Outrossim, favorecerem a planta pela produção de reguladores de crescimento e melhoria na absorção de nutrientes (Myoungsu et al., 2005).

Hernández-Rodríguez et al. (2008) relataram que rizobactérias (Burkholderia spp. e Pseudomonas fluorescens) exibiram efeito antagonista contra $F$. verticillioides $\mathrm{M} 1$ inoculado em milho. Pseudomonas fluorescens (cepas MKB 158 e MKB 249) e Pseudomonas frederiksbergensis (cepa 202) reduziram significativamente a gravidade de doenças causadas por Fusarium culmorum no trigo e na cevada (Khan \& Doohan, 2009).

O milho, por apresentar alto potencial produtivo, é uma das culturas mais exigentes em fertilizantes, sobretudo nitrogenados e fosfatados. O suprimento inadequado de nitrogênio e fósforo é um dos fatores limitantes ao rendimento de grãos. Aliadas a isto, plantas de milho expostas ao estresse por falta de fertilidade do solo são altamente susceptíveis à infecção por fungos toxigênicos (Blandino et al., 2008).

Apesar da perspectiva de utilização de rizobactérias com o propósito de bioproteção e crescimento vegetal, ainda é imprescindível o fornecimento de nutrientes para a cultura uma vez que a inoculaçao das bactérias não substitui a adubação porém pode promover melhor absorção e utilização dos nutrientes disponíveis (Saubidet et al., 2002). Contudo, as respostas da planta em relação à interação desses fatores ainda são desconhecidas haja vista que a fertilidade natural do solo, ou os níveis de adubação fornecidos podem influenciar o comportamento das bactérias quanto à sobrevivência, reprodução e eficiência de atuação, alterando o desenvolvimento da planta, a produtividade e a qualidade do produto.

Desta forma, o trabalho objetivou avaliar, em condições de campo, o efeito da inoculação com Pseudomonas fluorescens e níveis de adubação NPK na composição química e contaminação por fungos e fumonisinas, em grãos de milho.

\section{Material e Métodos}

O experimento foi conduzido no período de segunda safra (safrinha) de 2009, no município de Londrina (23 $22^{\prime}$ latitude Sul, $51^{\circ} 22^{\prime}$ longitude Oeste de Greenwich, com altitude de 580 m). O solo do local é caracterizado como Latossolo Vermelho eutroférrico e o clima da região, segundo a classificação de Köppen, é Cfa, ou seja, clima subtropical, com verões quentes, geadas pouco frequentes e tendência de concentração das chuvas nos meses de verão; apesar disto, sem estação seca definida (Caviglione et al., 2000). As temperaturas máximas e mínimas diárias, como a precipitação pluviométrica diária durante o período de condução do experimento, fornecidas pela estação metereológica do Instituto Agronômico do Paraná (IAPAR) situada a $5 \mathrm{~km}$ da área experimental, estão apresentadas na Figura 1.

Foram avaliados três níveis de adubação NPK (0, 50 e 100\% da indicação técnica para a cultura) e inoculação ou não de sementes com P. fluorescens. O delineamento experimental foi de bloco casualizado, em esquema fatorial $2 \times 3$ com quatro repetições. O híbrido de milho utilizado foi P30F35 (Pioneer) apresentando ciclo precoce, elevada capacidade de adaptação para a safrinha e alto potencial produtivo.

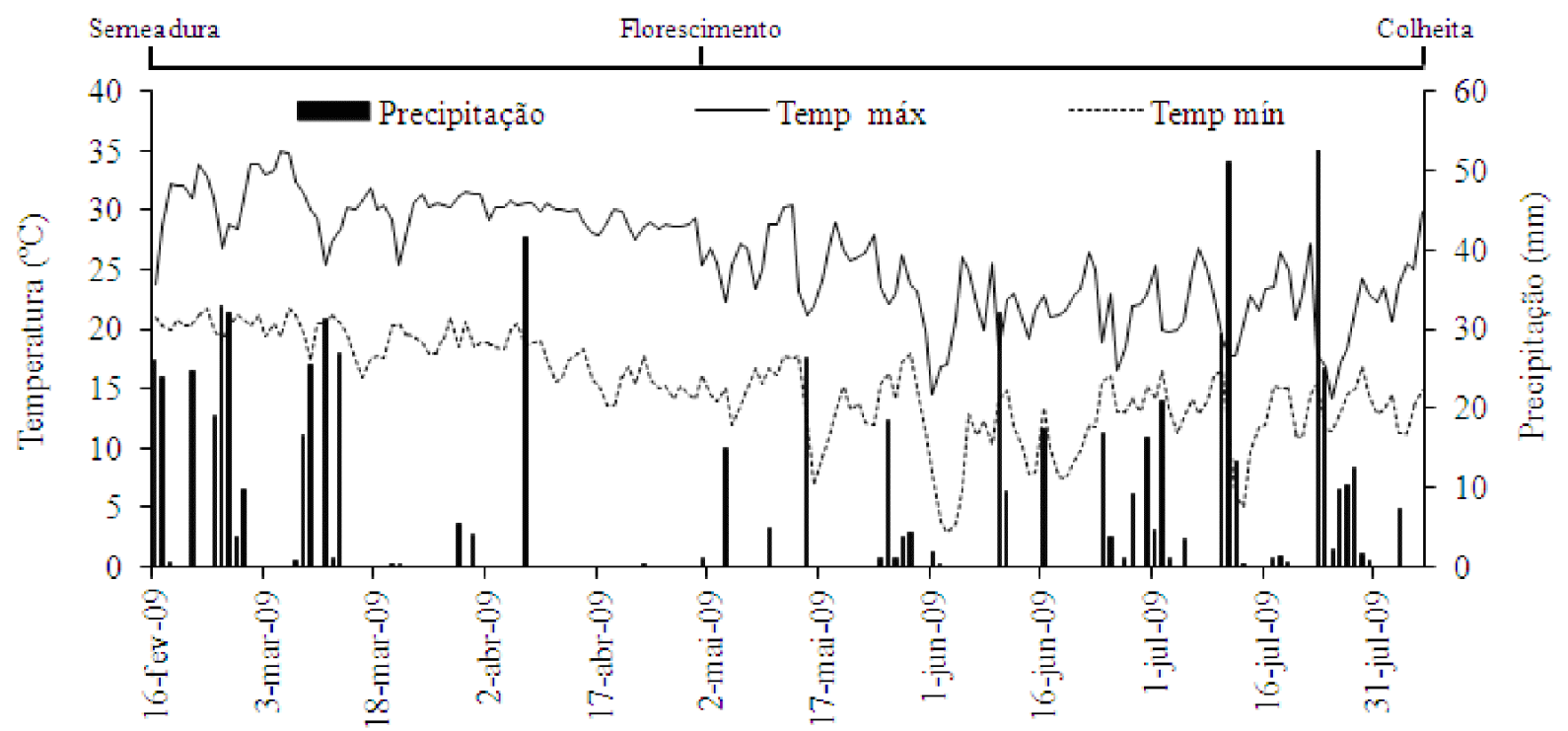

Figura 1. Dados diários de temperaturas máximas e míninas e de precipitação pluviométrica durante o período de condução do experimento 
As parcelas foram constituídas de quatro linhas de cinco metros de comprimento, com espaçamento entre linhas de 0,9 $\mathrm{m}$. Foram consideradas parcelas úteis as duas linhas centrais, desprezando-se $0,5 \mathrm{~m}$ das suas extremidades.

Previo à instalação do experimento foram coletadas amostras de solo para análise química da área experimental a 0-10 e 10-20 $\mathrm{cm}$ de profundidade (Tabela 1). Com base nesses resultados foi realizada a adubação do solo com nitrogênio, fósforo e potássio (N-P-K) no sulco da semeadura com o fertilizante formulado 08-28-16. Os tratamentos com 0, 50 e $100 \%$ da recomendação técnica corresponderam às quantidades de 0,125 e $250 \mathrm{~kg} \mathrm{ha}^{-1}$ do formulado (EMBRAPA, 2012).

Anterior à semeadura, as sementes que receberam o inoculante à base de $P$. fluorescens foram tratadas na dose de $140 \mathrm{~mL} \mathrm{ha}^{-1}$ (100 mL de Rizofos liq Maíz e $40 \mathrm{~mL}$ de Premax $\mathrm{R}$ Protector ${ }^{\circ}$ ). A semeadura foi realizada manualmente e, para atingir a densidade de aproximadamente 55 mil plantas ha ${ }^{-1}$, realizou-se desbaste quando as plantas apresentavam três folhas expandidas.

Durante o desenvolvimento da cultura a área foi monitorada com relação à pragas e plantas daninhas. Constatou-se a necessidade de aplicação de Teflubenzuron na dosagem de 100 $\mathrm{mL} \mathrm{ha}^{-1}$ para controle de vaquinha (Diabrotica speciosa) devido à desfolha ocasionada pelo inseto adulto no estádio V3 (Ritchie et al., 1986) além de eliminação de plantas daninhas, realizada mediante capina manual.

A adubação nitrogenada de cobertura foi realizada aos 35 dias após a emergência das plântulas (estádio V6) com aplicação de $80 \mathrm{~kg} \mathrm{ha}^{-1} \mathrm{de} \mathrm{N}$ (ureia) em todos os tratamentos. A colheita da área útil da parcela foi realizada manualmente quando os grãos apresentavam aproximadamente $20 \%$ de umidade; após a limpeza as amostras foram moídas a 30 mesh, realizando-se higienização do equipamento entre amostras (álcool 70\%) e armazenadas a $-18^{\circ} \mathrm{C}$ até o momento de uso.

$\mathrm{O}$ teor de proteína bruta foi determinado pelo método de Kjeldahl (AOAC, 1995) realizando-se a digestão da amostra (MOD TE-40/25 ), com posterior destilação (MOD TE-036/1") e conversão do teor total de $\mathrm{N}$ em proteína pelo uso do fator 6,25 . O teor de cinzas foi determinado segundo a pesagem dos resíduos da incineração em mufla (MOD 318D24") (IAL, 2008).

Para a contagem de bolores e leveduras $10 \mathrm{~g}$ de milho triturado (30 mesh) foram homogeneizados em $90 \mathrm{~mL}$ de água peptonada estéril $0,1 \%(\mathrm{v} / \mathrm{v})$ e submetidos a diluições seriadas $\left(10^{-1} \mathrm{a} 10^{-6}\right)$ em tubos contendo o mesmo diluente. Uma alíquota de $0,1 \mathrm{~mL}$ de cada diluição foi plaqueada em Ágar batata dextrose (BDA), acidificada a pH 4,0 com ácido tartárico. As placas foram incubadas a $25^{\circ} \mathrm{C}$, durante 5 dias (MOD TE-39, Tecnal') e os gêneros fúngicos identificados de acordo com Samson et al. (1995).
A determinação de fumonisinas foi realizada por CLAE de conformidade com a metodologia adaptada por Ueno et al. (1993). Para extração, um volume de $30 \mathrm{~mL}$ de metanol: água (3:1, v:v) foi adicionado a $10 \mathrm{~g}$ de amostra triturada (30 mesh), seguido de agitação a $150 \mathrm{rpm}$, por 1 hora, a $10^{\circ} \mathrm{C}$ (MOD MA-830/A'). Após filtração foi aplicado $1 \mathrm{~mL}$ do extrato bruto em coluna de troca aniônica (Sep-Pak accell plus QMA') previamente acondicionado com $5 \mathrm{~mL}$ de metanol seguido de $5 \mathrm{~mL}$ de metanol:água (3:1, v:v); em seguida, foram aplicados $6 \mathrm{~mL}$ de metanol:água (3:1, v:v) seguidos de $3 \mathrm{~mL}$ de metanol. As fumonisinas foram eluídas com $10 \mathrm{~mL}$ de solução de ácido acético $0,5 \%$ em metanol e o eluato seco a $40{ }^{\circ} \mathrm{C}$. O resíduo foi ressuspenso em $2 \mathrm{~mL}$ de metanol:água (3:1, v:v) secado sob gás $\mathrm{N}_{2}$ a $40{ }^{\circ} \mathrm{C}$ e novamente ressuspenso em $800 \mu \mathrm{L}$ de metanol:água (3:1, v:v). Alíquotas de $200 \mu \mathrm{L}$ foram secadas em gás $\mathrm{N}_{2}$ a $40^{\circ} \mathrm{C}$. Uma alíquota de $200 \mu \mathrm{L}$ foi ressuspensa em $100 \mu \mathrm{L}$ de acetonitrila:água (1:1), derivatizada com $200 \mu \mathrm{L}$ de o-phtaldialdeído (40 mg de OPA, $1 \mathrm{~mL}$ de metanol, $5 \mathrm{~mL}$ de borato de sódio a $0,1 \mathrm{~mol} \mathrm{~L}^{-1}$ e $50 \mu \mathrm{L}$ de 2 -mercaptoetanol) e as injeções foram feitas dentro de $1 \mathrm{~min}$, em CLAE. Fumonisinas foram analisadas em sistema isocrático de fase reversa, por CLAE (bomba LC-10 AD e detector de fluorescência (RF 535 ) usando-se a coluna $\mathrm{C}_{18}$ Luna $5 \mu(4,6 \times 250 \mathrm{~mm})$. Foi utilizado comprimento de onda de 335 e $450 \mathrm{~nm}$ de excitação e emissão, respectivamente. A fase móvel consistiu de metanol: fosfato de sódio $\left(\mathrm{CH}_{3} \mathrm{OH}: \mathrm{Na}_{2} \mathrm{HPO}_{4}\right)$ 0,1 M (80:20, v:v) ajustado com ácido o-fosfórico a pH 3,3, fluxo de $1 \mathrm{~mL} \mathrm{~min}{ }^{-1}$. O limite de detecção de $\mathrm{FB}_{1}$ e $\mathrm{FB}_{2}$ foi 27,5 e $35,3 \mathrm{ng} \mathrm{g}^{-1}$, respectivamente.

Os resultados obtidos foram submetidos à análise de variância (ANOVA) seguida do teste de comparação de médias por Tukey e correlação de Pearson, analisada pelo Teste-t $(\mathrm{p}<0,05)$ utilizando-se o programa Statistica for Windows versão 6.0. Os valores referentes à contagem de bolores e leveduras foram convertidos à escala logarítmica, antes de serem submetidos à análise estatística.

\section{Resultados e Discussão}

O teor de proteína dos grãos de milho variou entre 9,64 e 14,19\% (base seca); no entanto, os diferentes níveis de adubação, a presença/ausência de inoculação com $P$. fluorescens e a interação entre esses fatores, não exerceram efeitos significativos na porcentagem média de proteína nos grãos de milho $(\mathrm{p}>0,05$; Tabela 2).

Resultado similar foi relatado por Pommer \& Sawazaki (1981) ao verificarem que o teor percentual de proteína na matéria seca dos grãos de milho não foi alterado significativamente pela adubação contínua com NPK em ensaio no município de Campinas, SP; por outro lado, em Mococa, SP, o teor proteico

Tabela 1. Caracterização química do solo da área experimental

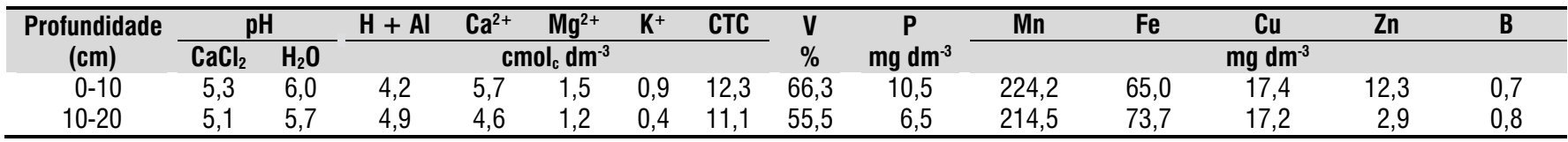

Extratores: Ca, Mg, Al: KCl; P, K, Mn, Fe, Cu, Zn: Mehlich 1; B: HCI 0,05N 
Tabela 2. Teores de proteína e cinzas em grãos de milho provenientes de cultivo sob diferentes níveis de adubação NPK e inoculação de sementes com Pseudomonas fluorescens

\begin{tabular}{lcc}
\hline \multicolumn{1}{c}{ Causas de variação } & Proteína (\%) & Cinzas (\%) \\
Adubação $\left(\mathrm{kg} \mathrm{ha}^{-1}\right)$ & & \\
0 & $11,74 \pm 1,29 \mathrm{a}$ & $1,60 \pm 0,27 \mathrm{a}$ \\
125 & $11,42 \pm 0,98 \mathrm{a}$ & $1,53 \pm 0,13 \mathrm{a}$ \\
250 & $11,52 \pm 1,1^{\mathrm{a}} \mathrm{a}$ & $1,67 \pm 0,16 \mathrm{a}$ \\
\hline Pseudomonas fluorescens & & \\
Não inoculada & $11,32 \pm 0,94 \mathrm{a}$ & $1,59 \pm 0,24 \mathrm{a}$ \\
Inoculada & $11,80 \pm 1,26 \mathrm{a}$ & $1,62 \pm 0,15 \mathrm{a}$ \\
\hline Valor de $\mathrm{F}$ & & \\
Adubação $(\mathrm{A})$ & $0,14^{\mathrm{ns}}$ & $0,59^{\text {ns }}$ \\
Inoculação $(\mathrm{I})$ & $1,06^{\mathrm{ns}}$ & $0,13^{\mathrm{ns}}$ \\
$\mathrm{A}$ *I & $1,60^{\mathrm{ns}}$ & $5,13^{*}$ \\
\hline
\end{tabular}

Média oriundas de 4 repetições \pm desvio padrão seguida pela mesma letra na coluna não diferem

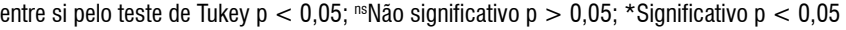

percentual foi influenciado significativamente pelo nitrogênio porém se sabe que as respostas à adubação são dependentes de condições climáticas, genótipo, do tipo de solo utilizado no experimento e da interação de fatores.

Rehman et al. (2011) observaram que os teores de proteína, amido e lipídeo no grão de milho foram menores quando não realizada adubação com NPK. Além disto, observou-se aumento no teor de proteína e amido, além de redução no teor de lipídeo no grão com o incremento na dose utilizada (300-150-150 kg NPK ha-1).

As condições climáticas durante o período de condução do experimento não foram adequadas para a cultura do milho ocorrendo escassez hídrica e baixa temperatura com registros de geadas, conforme demonstrado na Figura 1.

A produção da cultura de milho pode ficar comprometida se a deficiência hídrica coincidir com o período de florescimento, fase que determina a quantidade de óvulos a serem fecundados e, por consequência, a produção de grãos (Cardoso et al., 2004). Outrossim, a mobilização de nutrientes para os grãos de milho pode ter sido afetada uma vez que a absorção e a translocação de minerais pela planta requerem umidade no solo (Oktem, 2008) elucidando, assim, a ausência de efeito significativo dos teores médios de proteína nos grãos de milho no presente estudo em diferentes teores de adubação com NPK ( $p>0,05$; Tabela 2).
Com relação ao teor de cinzas, observaram-se variação de 1,53 a 1,67\% (base seca), a não inoculação/inoculação de sementes com $P$. fluorescens e os níveis de adubação NPK, avaliados isoladamente (Tabela 2) não surtiram efeitos significativos para os níveis médios de tal resposta $(\mathrm{p}>0,05)$ embora a interação entre esses fatores tenha resultado em efeito significativo na porcentagem média de cinzas $(\mathrm{p}<0,05$; Tabela 2).

Segundo Ferreira et al. (2001) a disponibilidade de minerais no solo influencia a composição mineral foliar e esta, por sua vez, a composição mineral dos grãos de milho. Por outro lado, as rizobactérias inoculadas nas culturas exercem efeitos benéficos ao promover o crescimento vegetal em virtude sobretudo do aumento da disponibilidade de nutrientes para as plantas, pela solubilização de fosfato inorgânico (Rodríguez \& Fraga, 1999) e pelo maior crescimento da raiz, favorecendo a absorção de nutrientes pelos grãos.

Conforme apresentado na Tabela 3, o milho apresentou contaminação natural por Fusarium spp. $\left(2,0 \times 10^{3}\right.$ a 2,1 x10 UFC $\mathrm{g}^{-1}$ ), Penicillium spp. (não detectável a $1,0 \times 10^{5} \mathrm{UFC}^{-1}$ ), Aspergillus spp. (não detectável a 2,0 $\times 10^{4} \mathrm{UFC} \mathrm{g}^{-1}$ ) e leveduras (não detectável a 9,0 × $10^{4} \mathrm{UFC}^{-1}$ ). Contaminação inicial por Fusarium spp., Penicillium spp. e Aspergillus spp. também foi relatada por Moreno et al. (2009) em milho proveniente das safras de 2003 e 2004 da região Norte do Paraná e por Richard et al. (2007) investigando a micoflora de milho maduro em silo na França.

A contaminação média por fumonisinas $\left(\mathrm{FB}_{1}+\mathrm{FB}_{2}\right)$ nos grãos variou entre 0,30 a $0,54 \mu \mathrm{g} \mathrm{g}^{-1}$ (Tabela 3 ). Embora alguns países, incluindo a Suíça e a Eslováquia, tenham os seus próprios regulamentos que definem os níveis máximos aceitáveis de fumonisinas em milho, não existe ainda uma legislação global para regular tais níveis.

O "Mycotoxin Committee of the American Association of Veterinary Laboratory Diagnosticans" estabelece os níveis máximos tolerados entre 5 e $50 \mu \mathrm{g} \mathrm{g}^{-1}\left(\mathrm{FB}_{1}+\mathrm{FB}_{2}+\mathrm{FB}_{3}\right)$ em milho destinado à alimentação de equinos, suínos, bovinos e aves (IARC, 2002). Já o "Food and Drug Administration" (FDA) estabeleceu, como valores totais de $\mathrm{FB}_{1}+\mathrm{FB}_{2}+\mathrm{FB}_{3}$ de até $4 \mu \mathrm{g}$ $\mathrm{g}^{-1}$ para o milho destinado ao consumo humano (Avantaggiato et al., 2002).

Tabela 3. Contaminação fúngica $\left(\log\right.$ UFC $\left.\mathrm{g}^{-1}\right)$ e por fumonisinas $\left(\mu \mathrm{g} \mathrm{g}^{-1}\right)$ de grãos de milho provenientes de cultivo em diferentes níveis de adubação NPK e inoculação das sementes com Pseudomonas fluorescens

\begin{tabular}{|c|c|c|c|c|c|c|}
\hline Causas de variação & Fusarium spp. & Penicillium spp. & Aspergillus spp. & Leveduras & $\mathrm{FB}_{1}$ & $\mathrm{FB}_{2}$ \\
\hline \multicolumn{7}{|l|}{ Adubação $\left(\mathrm{kg} \mathrm{ha}^{-1}\right)$} \\
\hline 0 & $4,88 \pm 0,38 a$ & $1,59 \pm 2,19 a$ & $0,50 \pm 1,41 a$ & $1,20 \pm 2,23 a$ & $0,26 \pm 0,26 a$ & $0,12 \pm 0,17 a$ \\
\hline 125 & $5,18 \pm 0,67 a$ & $1,03 \pm 1,97 a$ & $0,37 \pm 1,06 a$ & $0,61 \pm 1,75 a$ & $0,34 \pm 0,45 a$ & $0,20 \pm 0,35 a$ \\
\hline 250 & $5,10 \pm 0,94 a$ & $1,53 \pm 2,14 \mathrm{a}$ & $0,53 \pm 1,52 a$ & $0,68 \pm 1,93 a$ & $0,23 \pm 0,27 a$ & $0,10 \pm 0,13 a$ \\
\hline \multicolumn{7}{|l|}{ P. fluorescens } \\
\hline Não inoculada & $4,92 \pm 0,71 \mathrm{a}$ & $1,66 \pm 2,10 a$ & $0,25 \pm 0,86 a$ & $0,45 \pm 1,57 \mathrm{a}$ & $0,20 \pm 0,20 a$ & $0,10 \pm 0,14 a$ \\
\hline Inoculada & $5,19 \pm 0,60 a$ & $1,10 \pm 2,00 \mathrm{a}$ & $0,69 \pm 1,61 \mathrm{a}$ & $1,21 \pm 2,20 \mathrm{a}$ & $0,35 \pm 0,41 \mathrm{a}$ & $0,18 \pm 0,30 a$ \\
\hline \multicolumn{7}{|l|}{ Valor de F } \\
\hline Adubação (A) & $0,36^{\text {ns }}$ & $0,00^{\text {ns }}$ & $0,00^{\text {ns }}$ & $0,33^{\text {ns }}$ & $0,03^{\text {ns }}$ & $0,02^{\text {ns }}$ \\
\hline Inoculação (I) & $0,86^{\text {ns }}$ & $0,41^{\mathrm{ns}}$ & $0,63^{\text {ns }}$ & $1,06^{\text {ns }}$ & $1,37^{\mathrm{ns}}$ & $0,68^{\text {ns }}$ \\
\hline$A * 1$ & $0,50^{\text {ns }}$ & $0,67^{\mathrm{ns}}$ & $0,00^{\text {ns }}$ & $4,36^{\star}$ & $2,44^{\mathrm{ns}}$ & $1,57^{\mathrm{ns}}$ \\
\hline
\end{tabular}

Médias oriundas de 4 repetições \pm desvio padrão seguidas pela mesma letra na coluna não diferem entre si pelo teste de Tukey $p<0,05$; ns Não significativo $p>0,05$; ${ }^{*}$ Significativo $p<0,05$ 
Tabela 4. Correlação simples entre diferentes níveis de adubação NPK, inoculação com Pseudomonas fluorescens, teor de proteína e cinzas e contaminação fúngica e por fumonisinas de grãos de milho

\begin{tabular}{|c|c|c|c|c|c|c|c|c|c|c|}
\hline \multirow{2}{*}{ Variáveis } & \multirow{2}{*}{$\begin{array}{l}\text { Níveis de } \\
\text { adubação }\end{array}$} & \multirow{2}{*}{ Inoculação } & \multirow{2}{*}{ Proteína } & \multirow{2}{*}{ Cinzas } & \multicolumn{2}{|c|}{ Fumonisinas } & \multirow{2}{*}{ Fusarium spp. } & \multirow{2}{*}{ Penicillium spp. } & \multirow{2}{*}{ Aspergillus spp. } & \multirow{2}{*}{ Leveduras } \\
\hline & & & & & $\mathrm{FB}_{1}$ & $\mathrm{FB}_{2}$ & & & & \\
\hline & $\rho=1,00$ & $\rho=0,00$ & $\rho=-0,08$ & $\rho=0,15$ & $\rho=-0,03$ & $\rho=-0,03$ & $\rho=0,12$ & $\rho=-0,01$ & $\rho=0,01$ & $\rho=-0,11$ \\
\hline Aqudoaçãa & $p=---$ & $p=1,00$ & $p=0,70$ & $p=0,48$ & $p=0,86$ & $p=0,86$ & $p=0,54$ & $p=0,95$ & $p=0,95$ & $p=0,59$ \\
\hline Inمcularãn & & $\rho=1,00$ & $\rho=0,21$ & $\rho=0,07$ & $\rho=0,24$ & $\rho=0,17$ & $\rho=0,19$ & $\rho=-0,14$ & $\rho=0,17$ & $\rho=0,20$ \\
\hline Inoculaçao & & & $p=0,31$ & $p=0,74$ & $p=0,25$ & $p=0,41$ & $p=0,35$ & $p=0,51$ & $p=0,41$ & $p=0,34$ \\
\hline Proteína & & & $\rho=1,00$ & $\rho=0,57^{*}$ & $\rho=0,16$ & $\rho=0,18$ & $\rho=0,31$ & $\rho=0,18$ & $\rho=-0,36$ & $\rho=0,00$ \\
\hline riverila & & & $p=---$ & $p=0,00$ & $p=0,43$ & $p=0,39$ & $p=0,12$ & $p=0,39$ & $p=0,07$ & $p=1,00$ \\
\hline Cinzas & & & & $\rho=1,00$ & $\rho=0,16$ & $\rho=0,15$ & $\rho=0,15$ & $\rho=-0,00$ & $\rho=-0,11$ & $\rho=0,01$ \\
\hline Cinzas & & & & $p=---$ & $p=0,44$ & $p=0,45$ & $p=0,47$ & $p=0,99$ & $p=0,59$ & $p=0,95$ \\
\hline$F R_{1}$ & & & & & $\rho=1,00$ & $\rho=0,94^{*}$ & $\rho=-0,11$ & $\rho=-0,37$ & $\rho=0,16$ & $\rho=0,14$ \\
\hline$F B_{1}$ & & & & & $p=--$ & $p=0,00$ & $p=0,58$ & $p=0,07$ & $p=0,44$ & $p=0,51$ \\
\hline$F B_{2}$ & & & & & & $\rho=1,00$ & $\rho=-0,22$ & $\rho=-0,31$ & $\rho=0,03$ & $\rho=0,27$ \\
\hline $\mathrm{FB}_{2}$ & & & & & & $p=---$ & $p=0,28$ & $p=0,13$ & $p=0,85$ & $p=0,19$ \\
\hline Fusarium sno & & & & & & & $\rho=1,00$ & $\rho=0,11$ & $\rho=0,06$ & $\rho=-0,40^{*}$ \\
\hline & & & & & & & $p=---$ & $p=0,59$ & $p=0,76$ & $p=0,04$ \\
\hline Penicillium spp. & & & & & & & & $\rho=1$ & $\rho=0,02$ & $\rho=0,39$ \\
\hline & & & & & & & & $p=---$ & $p=0,90$ & $p=0,05$ \\
\hline Aspergillus spp. & & & & & & & & & $\begin{array}{c}\rho=1,00 \\
p=---\end{array}$ & $\begin{array}{l}\rho=0,15 \\
p=0,46\end{array}$ \\
\hline Leveduras & & & & & & & & & & $\rho=1,00$ \\
\hline & & & & & & & & & & $p=---$ \\
\hline
\end{tabular}

*Correlações significativas a $p<0,05 ; \rho$ - Correlações; $p$ - Nível de significância

No Brasil e segundo a Resolução - RDC $n^{\circ} 7$ de 18 de fevereiro de 2011, desde de janeiro de 2014 é de $5 \mu \mathrm{g} \mathrm{g}^{-1} \mathrm{o}$ limite máximo tolerado (LMT) de fumonisinas $\left(\mathrm{FB}_{1}+\mathrm{FB}_{2}\right)$ em grãos de milho destinado posteriormente ao processamento (Brasil, 2011). Desta forma, o milho avaliado no presente estudo, safra de 2009, apresentou níveis de fumonisinas totais $\left(\mathrm{FB}_{1}+\mathrm{FB}_{2}\right)$ enquadrados dentro dos limites máximos estabelecidos pelos órgãos nacional e internacional.

A contaminação reduzida de fumonisinas pode ser relativa à fertilidade natural do solo aliada à adubação nitrogenada fornecida, proporcionando uma adubação balanceada aumentando, então, a resistência das plantas. Blandino et al. (2008) relataram que, por falta de nitrogênio, o estresse aumenta significativamente a contaminação de milho por $\mathrm{FB}_{1}$. Paralelamente, os baixos níveis de fumonisinas podem ter sido reflexo também das condições climáticas (restrições hídricas) durante o desenvolvimento da cultura no campo (Figura 1). Pereira et al. (2010) observaram que altos níveis de fumonisinas foram obtidos em milho, na safra de 2007-2008, com alta precipitação pluviométrica que ocorreu da floração à maturidade, em comparação com a safra de 2006-2007.

Os níveis de adubação, a presença/ausência de inoculação com $P$. fluorescens e a interação entre esses fatores, não se mostraram significativos para a contaminação fúngica e por fumonisinas; exceção foi encontrada para os resultados de contaminação por levedura, ocorrendo efeito significativo negativo da interação entre os níveis de adubação e inoculação demonstrando que a adubação com maiores níveis de NPK aliada à utilização da rizobactéria, dificultou a contaminação por parte desses microrganismos. As rizobactérias são conhecidas por colonizarem rapidamente a rizosfera e reduzir microrganismos nocivos, bem como fitopatógenos na superfície radicular (Rangajaran et al., 2003).
Em condições de campo, Khan \& Doohan (2009) demonstraram a capacidade de duas cepas de $P$. fluorescens (MKB 158 e MKB 249) e de P. frederiksbergensis (MKB 202) na redução da contaminação de grãos de trigo por desoxinivalenol (DON), micotoxina produzida sobremaneira por Fusarium graminearum; os autores verificaram diminuição de $12 \mathrm{e}$ $21 \%$ de DON em plantas borrifadas com suspensão de $P$. frederiksbergensis ( $24 \mathrm{~h}$ pré-inoculação do patógeno) e 74-78\% com o uso das duas cepas de P. fluorescens.

Observou-se correlação significativa, porém negativa, entre a contagem de leveduras e Fusarium spp., indicando haver competição entre esses dois microrganismos $(\rho=-0,40$; $p<$ 0,05 ; Tabela 4). Desta maneira, os resultados demonstram que, simultaneamente à redução da contagem de leveduras, com o aumento da dose de adubação e inoculação com P. fluorescens, há condições propícias ao crescimento de Fusarium spp.

Além de comprometer o desenvolvimento e o potencial produtivo da cultura do milho, supõe-se que as condições climáticas desfavoráveis (restrições hídricas e geadas, Figura 1) também afetaram a sobrevivência, a estabilidade, a multiplicação e a associação das rizobactérias com a cultura; desta forma, torna-se imprescindível dar continuidade aos estudos com $P$. fluorescens na cultura do milho em condições climáticas favoráveis, em que a adubação e a inoculação com $P$. fluorescens possam expressar seus possíveis efeitos sobre o desenvolvimento e nutrição da planta, proteção contra patógenos e, consequentemente, sobre a qualidade do grão.

\section{Conclusões}

1. A inoculação com $P$. fluorescens e a adubação NPK não resultaram em efeito individual significativo na composição química (proteína e cinzas), contaminação fúngica (bolores e leveduras) e fumonisinas $\mathrm{B}_{1}\left(\mathrm{FB}_{1}\right)$ e $\mathrm{B}_{2}\left(\mathrm{FB}_{2}\right)(\mathrm{p}>0,05)$. 
2. O incremento na adubação NPK resultou, aliado ao uso de $P$. fluorescens, em aumento no teor de cinzas $(\mathrm{p}<0,05)$ e redução na contaminação do grão por leveduras $(\mathrm{p}<0,05)$ o que favoreceu o crescimento de Fusarium spp. $(r=-0,40 ; \mathrm{p}<0,05)$.

\section{Agradecimentos}

Os autores agradecem ao Conselho Nacional de Pesquisa e ao Desenvolvimento Científico Tecnológico (CNPq) em associação com o Ministério da Agricultura, Pecuária e Abastecimento (MAPA), à Fundação Araucária, ao UGF - Fundo Paraná-SETI e à CAPES (Coordenação de Aperfeiçoamento de Pessoal de Nível Superior) - Projeto Nanobiotecnologia no 23 , pelo suporte financeiro.

\section{Literatura Citada}

AOAC - Association of Official Analytical Chemists. Official methods of analysis. 16. ed. Washington: AOAC, 1995. v.1-2.

Avantaggiato, G.; Quaranta, F.; Desiderio, E.; Visconti, A. Fumonisin contamination of maize hybrids visibly damaged by Sesamia. Journal of the Science of Food and Agriculture, v.83, p.13-18, 2002.

Blandino, M.; Reyneri, A.; Vanara, F. Influence of nitrogen fertilization on mycotoxin contamination of maize kernels. Crop Protection, v.27, p.222-230, 2008.

Brasil - Ministério da Saúde. Resolução RDC n. 7, de 18 de fevereiro de 2011. Regulamento técnico sobre limites máximos tolerados (LMT) para micotoxinas em alimentos. Diário Oficial da República Federativa do Brasil, Brasília, Seção 1, n.46, p.66, 3, 2011.

Cardoso, C. O.; Faria, R. T.; Folegatti, M. V. Simulação do rendimento e riscos climáticos para o milho safrinha em Londrina-PR, utilizando o modelo CERES-Maize. Engenharia Agrícola, v.24, p.291-300, 2004.

Caviglione, J. H.; Kiihl, L. R. B.; Caramori, P. H.; Oliveira, D. Cartas climáticas do Paraná. 2000. <http://www.iapar.br/ modules/conteudo/conteudo.php?conteudo=597>. $21 \mathrm{Fev}$. 2013.

EMBRAPA - Empresa Brasileira de Pesquisa Agropecuária. Nutrição e adubação do milho.2012. <http://www.cnpms. embrapa.br/publicacoes/milho_8_ed/feraduba.htm>. 15 Fev. 2013.

Ferreira, A. C. B.; Araújo, G. A. A.; Pereira, P. R. G.; Cardoso, A. A. Características agronômicas e nutricionais do milho adubado com nitrogênio, molibdênio e zinco. Scientia Agricola, v.58, p.131-138, 2001.

Hernández-Rodríguez, A.; Heydrich-Pérez, M.; AceboGuerrero, Y.; Velazquez-Del Valle, M. G.; HernándezLauzardo, A. N. Antagonistic activity of Cuban native rhizobacteria against Fusarium verticillioides (Sacc.) Nirenb. in maize (Zea mays L.). Applied Soil Ecology, v.39, p.180186, 2008.

IAL - Instituto Adolfo Lutz. Normas Analíticas do Instituto Adolfo Lutz. 4.ed. São Paulo: IAL, 2008. 105p.
IARC - International Agency for Research on Cancer. Some traditional herbal medicines, some mycotoxins, naphthalene and styrene. In: IARC Monographs on the Evaluation of Carcinogenic Risks to Human. 2002, v.82, p.301-366.

Kanampiu, F. K; Friesen, D.; Gressel, J. CIMMYT collaborative efforts unveil herbicide-coated maize seed technology to curb problematic Striga. Integrated Pest Management Reviews, v.7, p.63-64, 2002.

Khan, M. R.; Doohan, F. M. Bacterium-mediated control of Fusarium head blight disease of wheat and barley and associated mycotoxin contamination of grain. Biological Control, v.48, p.42-47, 2009.

Moreno, E. C.; Garcia, G. T.; Ono, M. A.; Vizoni, E.; Kawamura, O.; Hirooka, E. Y.; Ono, E. Y. S. Co-occurrence of mycotoxins in corn samples from the Northern region of Paraná State, Brazil. Food Chemistry. v.116, p.220-226, 2009.

Myoungsu, P.; Chungwoo, K.; Jinchul, Y.; Hyoungseok, L.; Wansik, S.; Seunghwan, K.; Tongmin, S. Isolation and characterization of diazotrophic growth promoting bacteria from rhizosphere of agricultural crops of Korea. Research in Microbiology, v.160, p.127-133, 2005.

Norred, W. P. Fumonisins-mycotoxins produced by Fusarium moniliforme. Journal of Toxicology and Environmental Health, v.38, p.309-328, 1993.

Oktem, A. Effect of water shortage on yield, and protein and mineral compositions of drip-irrigated sweet corn in sustainable agricultural systems. Agricultural Water Management, n.95, p.1003-1010, 2008.

Pereira, P.; Nesci, A.; Castillo, C.; Etcheverry, M. Impact of bacterial biological control agents on fumonisina $\mathrm{B}_{1}$ content and Fusarium verticillioides infection of field-grown maize. Biological Control, v.53, p.258-266, 2010.

Pommer, C. V.; Sawazaki, E. Influência da adubação mineral continua na produção de proteína e no seu teor percentual nos grãos de milho. Bragantia, v.40, p.103-108, 1981.

Rangajaran, S.; Saleena, L. M.; Vasudevan, P.; Nair, S. Biological suppression of rice diseases by Pseudomonas spp under saline soil conditions. Plant Soil, v.251, p.73-82, 2003.

Rehman, A.; Saleem, M. F.; Safdar, M. E.; Hussain, S.; Akhtar, $\mathrm{N}$. Grain quality, nutrient use efficiency, and bioeconomics of maize under different sowing methods and NPK levels. Chilean journal of agricultural research, v.71, p.586-593, 2011.

Richard, E.; Heutte, N.; Sage, L.; Pottier, D.; Bouchart, P.; Lebailly, P.; Garon, D. Toxigenic fungi and mycotoxins in mature corn silage. Food and Chemical Toxicology, v.45, p.2420-2425, 2007.

Ritchie, S. W.; Hanway, J. J.; Benson, G. O. How a corn plant develops. Ames: Iowa State University of Science and Technology, 1986. 21p. Special report no 48

Rodríguez, H.; Fraga, R. Phosphate solubilizing bacteria and their role in plant growth promotion. Biotechnology Advances, v.17, p.319-339, 1999.

Samson, R. A.; Hoeskstra, E. S.; Frisvad, J. C. Introduction to food-borne fungi. 4.ed. The Netherlands: Centraalbureau voor Schimmelcultures, 1995. 322p. 
Saubidet, M. I.; Fatta, N.; Barneix, A. J. The effect of inoculation with Azospirillum brasilense on growth and nitrogen utilization by wheat plants. Plant and Soil, v.245, p.215222, 2002.

Ueno, Y.; Aoyama, S.; Sugiura, Y.; Wang, D. S.; Hirooka, E. Y.; Hara, S.; Karki, T.; Chen, G.; Yu, S. H. A limited survey of fumonisin in corn and corn-based products in Asian countries. Mycotoxin Research, v.9, p.27-34, 1993.
USDA - United States Department of Agriculture. World Agricultural Supply and Demand Estimates. May 2013. < http://www.usda.gov/oce/commodity/wasde/latest.pdf $>$. 5 Jun. 2013.

Waes, J. G. van; Voss, K. A; Stevens, V. L.; Speer, M. C.; Riley, R. T. Maternal fumonisin exposure as a risk factor for neural tube defects. Advances in Food and Nutrition Research, v.56, p.145-181, 2009. 